\title{
Integrated Synthetic, Biophysical and Computational Investigations of Covalent Inhibitors of Prolyl Oligopeptidase and Fibroblast Activation Protein $\alpha$
}

\author{
Jessica Plescia, ${ }^{\ddagger}, 1$ Stéphane De Cesco, ${ }^{\ddagger},{ }^{+1}$ Mihai Burai Patrascu, ${ }^{\ddagger}, 1$ Jerry Kurian, ${ }^{1}$ Justin Di \\ Trani, ${ }^{1}$ Caroline Dufresne, ${ }^{1}$ Naëla Janmamode, ${ }^{1}$ Anthony K. Mittermaier, ${ }^{l}$ and Nicolas \\ Moitessier*
}

${ }^{1}$ Department of Chemistry, McGill University, 801 Sherbrooke Street West, Montreal, QC, Canada H3A 0B8

\begin{abstract}
Over the past decade, there has been an increasing interest in covalent inhibition as a drug design strategy. Our own interest in the development of prolyl oligopeptidase (POP) and fibroblast activation protein $\alpha$ (FAP) covalent inhibitors has led us to question whether these two serine proteases were equal in terms of their reactivity towards electrophilic warheads. To streamline such investigations, we exploited both computational and experimental methods to investigate the influence of different reactive groups on both potency and binding kinetics, using both our own series of POP inhibitors and others' discovered hits. A direct correlation between inhibitor reactivity and residence time was demonstrated through quantum mechanics (QM) methods and further supported by experimental studies. This computational method was also successfully applied to FAP, as an overview of known FAP inhibitors confirmed our computational predictions that more reactive warheads (e.g., boronic acids) must be employed to inhibit FAP than for POP.
\end{abstract}
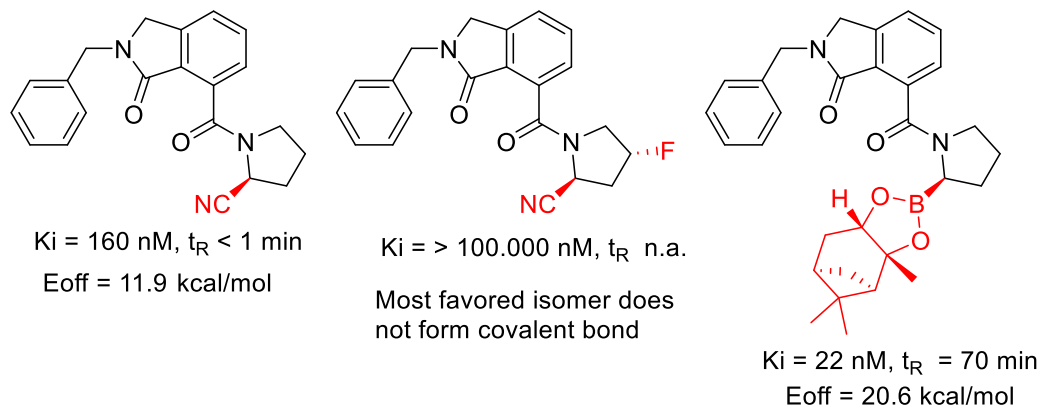

\section{Introduction}

Following the resurgence of covalent inhibition in the last decade, ${ }^{1-3}$ kinases and serine proteases have been targeted with numerous covalent inhibitors, ${ }^{4}$ and covalent inhibitors have reached the market (Figure 1). Among these targets are prolyl oligopeptidase (POP), initially associated with neurodegenerative diseases, ${ }^{5-8}$ and fibroblast activation protein $\alpha$ (FAP), a promising target for anti-cancer therapies. ${ }^{9-12}$ In the past, our group and others have reported a number of potent covalent POP inhibitors, ${ }^{8}$ including Cbz-Pro-Prolinal (1), JTP-4819 (2), KYP-2047 (3), and 
bicyclic derivative $\mathbf{5},{ }^{13}$ as well as FAP covalent inhibitors such as compounds $\mathbf{6}, \mathbf{8}$, and Talabostat (Figure 2). Although these two druggable targets have been inhibited by many covalent inhibitors, the major differences lie in the chemical nature of the warheads, or electrophilic functional groups that form covalent bonds with protein residues.
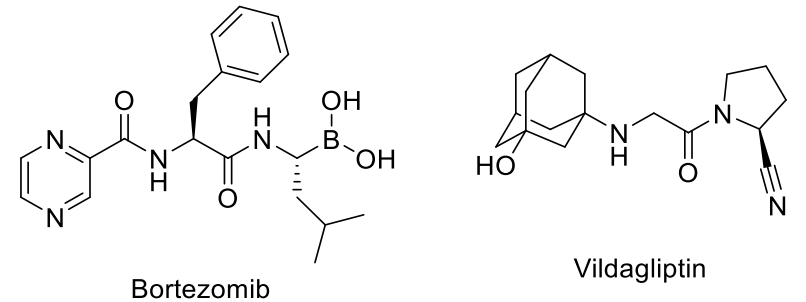

Figure 1. Selected marketed covalent inhibitors.

Non-covalent inhibitors often bind and dissociate very quickly and exhibit short residence times and are therefore often largely under thermodynamic control. In contrast, covalent inhibitors are believed to often bind in a two-step process (Figure 3a): a fast, non-covalent initial binding followed by a slower covalent bond formation. As a result, kinetic factors and residence time cannot be ignored and could indeed be critical for inhibitor efficacy. ${ }^{3}$ In particular, the reactivity of the warheads used in covalent inhibition has scarcely been investigated either experimentally ${ }^{14,15}$ or computationally ${ }^{16}$ despite the fact that reactivity often dictates whether the inhibitor will bind reversibly or irreversibly. Furthermore, the reactivity of the protein's catalytic residues in covalent inhibition has seldom been investigated. ${ }^{17}$

Prior to designing covalent inhibitors, the biological target must be first identified as covalently druggable (i.e., can be targeted with covalent inhibitors). Unfortunately, there are very few tools currently available, experimental or computational, to accomplish this. We report herein a developed computational protocol using POP and FAP that could eventually be used to (1) predict whether an enzyme is covalently druggable and (2) to identify potentially potent warheads. To illustrate the potential application of such a protocol: it took our team months to optimally express and purify POP and to optimize the in vitro activity assays, which was followed by months of synthesis until we found potent inhibitors. With our current computational protocol in hand, requiring only 2-3 weeks of calculations, we would have been able to make a more informed decision on whether to initiate our hit-discovery endeavor. Similarly, until this protocol was available, our efforts focused on the unsuccessful development of nitrile-containing FAP inhibitors. Running reactivity predictions before synthesis would have allowed us to opt for the appropriate warheads much earlier. 


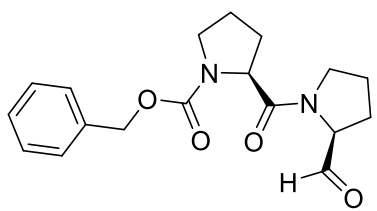

1, Cbz-Pro-Prolinal POP: $K_{\mathrm{i}}=0.35 \mathrm{nM}$

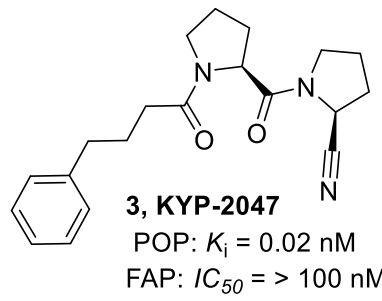

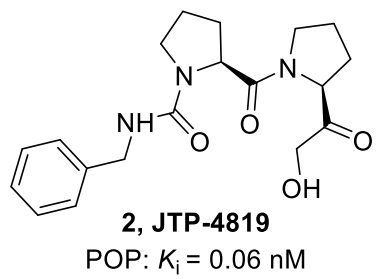

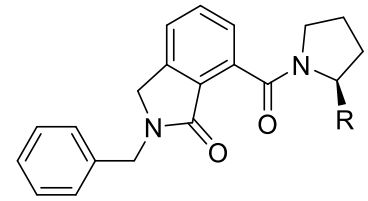

4, $\mathrm{R}=\mathrm{H}, K_{\mathrm{i}}=160 \mathrm{nM}(\mathrm{hPOP})$

$5, \mathrm{R}=\mathrm{CN}, K_{\mathrm{i}}=25 \mathrm{nM}(\mathrm{hPOP})$<smiles>[R]C(NC(=O)c1ccncc1)C(=O)N1CCC[C@H]1B(O)O</smiles>

6, $\mathrm{R}_{1}=\mathrm{Me}, \mathrm{R}_{2}=\mathrm{H}$, POP: $I C_{50}>10,000 \mathrm{nM}$ FAP: $I C_{50}>36 \mathrm{nM}$ 7, $\mathrm{R}_{1}=\mathrm{H}, \mathrm{R}_{2}=\mathrm{iPr}$, POP: $I C_{50}=1.3 \mathrm{nM}$ FAP: $I C_{50}>100,000 \mathrm{nM}$

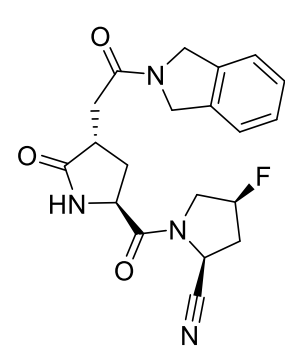

FAP: $I C_{50}=20 \mathrm{nM}$

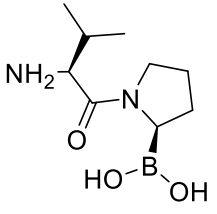

9, Talabostat FAP: $I C_{50}=66 \mathrm{nM}$ POP: $I C_{50}=980 \mathrm{nM}$ DPP-IV: $I C_{50}=22 \mathrm{nM}$

Figure 2. Selected POP inhibitors.

As demonstrated via co-crystallization, ${ }^{18,19}$ POP inhibition can be achieved through covalent bond formation between the reactive group of a ligand and the catalytic serine in the active site (Ser554). The reaction of Ser554 with aldehyde 1 leads to the formation of a hemiacetal, which favorably mimics the tetrahedral intermediate of the endogenous catalytic reaction, stabilizing its presence in the active site (Figures $3 \mathrm{~b}, 3 \mathrm{c}$ ). In contrast, reaction with a nitrile group leads to a trigonal planar iminoether, an intermediate which less favorably mimics the amide group of the peptide substrates (Figure 3d). While maintaining favorable non-covalent interactions (e.g. via the scaffold) is essential for both potency and selectivity, modification of the covalent warhead is also expected to have a significant impact on the binding affinity and kinetics via its influence on the second step of the binding event (Figure 3a).

a) $E+I \stackrel{k_{1}}{\underset{k_{-1}}{\rightleftharpoons}} E \cdots I \frac{k_{2}}{k_{-2}} E-I$

b)

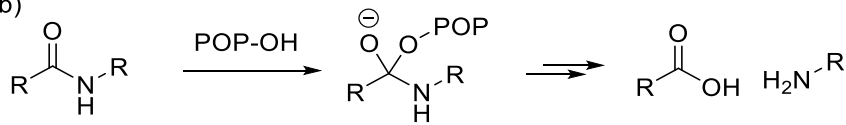

c)

d)
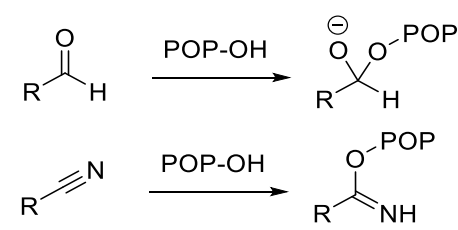


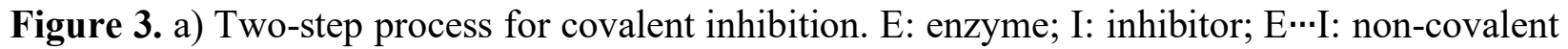
complex; $k_{1}$ : association rate constant; $k_{-1}$ : dissociation rate constant. b) cleavage of a substrate; b) aldehyde inhibitor covalent binding; c) nitrile inhibitor covalent binding.

Herein, we describe our collaborative approach, including computational predictions and experimental evaluations, to the investigation of the relative reactivities of FAP and POP and the nature of the covalent warheads that are more likely to lead to potent inhibitors.

\section{Strategy}

We sought to develop a computational protocol which would first be tested against experimental data collected on POP and then validated on a homologous enzyme, FAP (Figure 4).

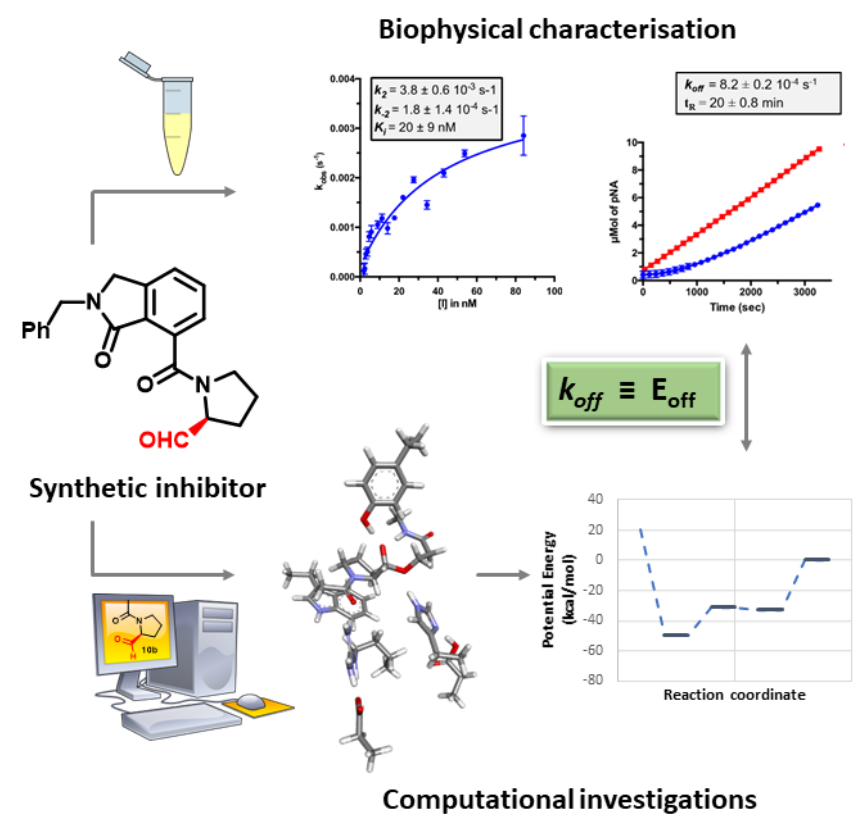

Figure 4. Computational model and experimental data collection. The residence times of various inhibitors depends on kinetics factors $\left(t_{R}=1 / k_{o f f}\right)$, which are measured using biophysical methods. These kinetic parameters are related to the energy required for the inhibitors to break the covalent bond and leave the enzyme ( $\left.E_{\text {off }}\right)$. Advantageously, $E_{\text {off }}$ can be computed, ultimately demonstrating that computations can substitute complex, time-consuming, and expensive experiments for initial assessments as to whether a newly discovered target is covalently druggable.

In order to probe the impact of the intrinsic reactivity of the warhead on the overall binding process, we designed a series of inhibitors 5a, 10a-17a which complement previously reported inhibitors 5c, 11c, 13c-15 $\mathbf{c}^{20}$ (Figure 5). Two strategies were envisioned: (1) substitution of the warhead - the nitrile, aldehyde, and boronic acid were selected, as these are known to form covalent bonds with nucleophilic protein residues, ${ }^{21,22}$ and (2) modification of the electronic environment of a given warhead - electron withdrawing fluorine atoms could be introduced on the nitrile analogue, a strategy exploited to prepare FAP inhibitors (Figure 2). 

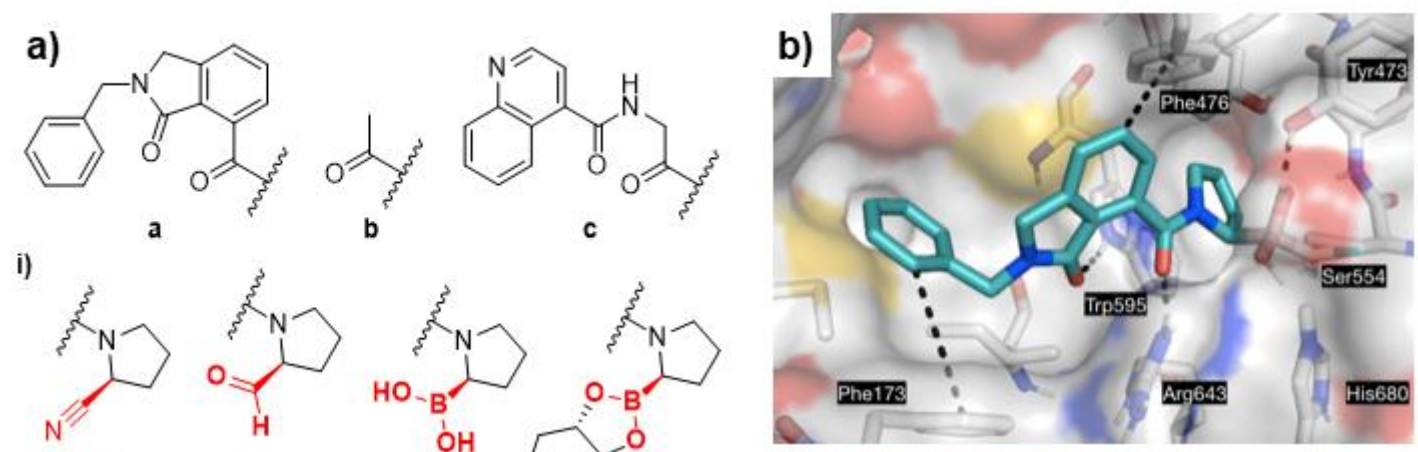

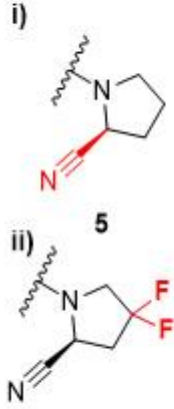

13

iii)

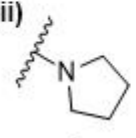

4
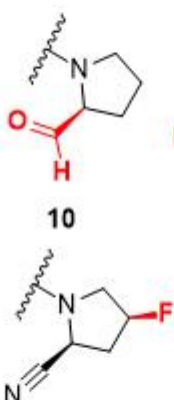

14

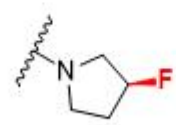

16
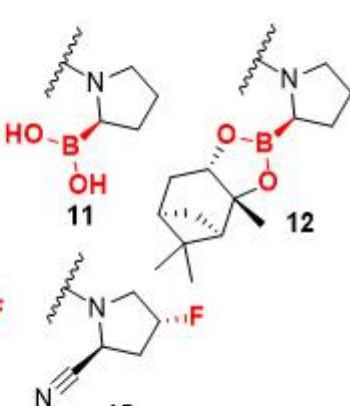

15

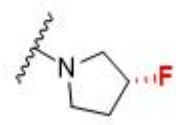

17

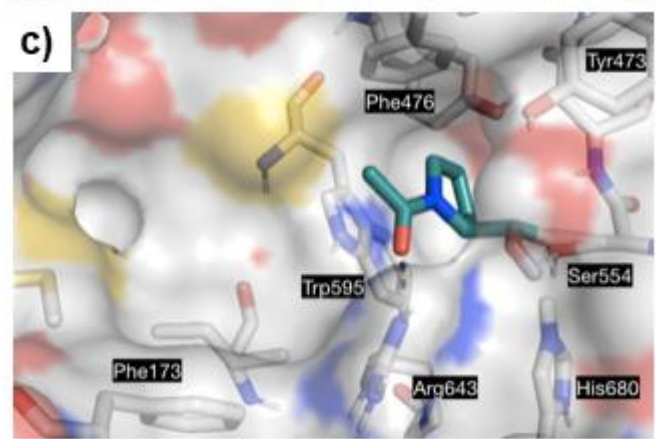

Figure 5. Selected inhibitor structures. i) different reactive groups; ii) modulated nitrile reactivity; iii) effects of fluorine atoms alone. b) Docked binding mode of boronic acid 11a into the POP active site. c) Snapshot of the POP active site and with 10b bound to Ser554 and the residues kept for the Quantum Chemical Cluster Approach (QCCA) study.

\section{Chemistry}

The synthesis of bicyclic scaffold a, previously published by our group, has been optimized and is presented in Scheme S1 in the Supporting Information. ${ }^{13}$ Bicyclic precursor 18 (Scheme 1), previously discovered through a virtual screening/virtual optimization strategy, was selected because of its straightforward and efficient synthesis. More specifically, this core was readily available in only three synthetic steps and an overall yield of $74 \%$ with no flash chromatography purification, offering the unprotected carboxylic acid $\mathbf{1 8}$ as a diversity point.

The individual proline analogs were then coupled to the scaffold $\mathbf{1 8}$ to afford the desired inhibitors. Because the proline analogues were either commercially or readily available, expedient and efficient synthesis of potential POP inhibitors was achieved in only 1-2 steps. The synthesis of these selected analogues (4a, 5a and 10a-17a) is outlined in Schemes 1 and 2.

The boron-containing analogue $\mathbf{1 2 a}$ was obtained by coupling scaffold $\mathbf{1 8}$ with the commercially available proline analog 19 to yield product 12a in moderate yield (Scheme 1). Attempts at hydrolysis of boronic ester 12a to obtain boronic acid 11a were unsuccessful, exhibiting solubility issues and yielding complex mixtures, so 12a was utilized instead. Our own liquid chromatography-mass spectrometry experiment revealed that the boronic ester 12a is completely hydrolyzed to boronic acid 11a in the assay buffer (Figure S1), and can therefore be tested as a pro-drug cleaved in the assay. Furthermore, our own in vitro assay controls show that the cleaved pinanediol exhibits no inhibitory activity against POP (data not shown). 
Synthesis of the potential inhibitor 10a bearing an aldehyde as the warhead started with the coupling of commercially available L-prolinol with scaffold 18, to afford the primary alcohol $\mathbf{2 0}$ in excellent yield. Further oxidation under Swern conditions led to the desired aldehyde 10a. Synthesis of the non-covalent analog $\mathbf{4 a}$ was accomplished by coupling scaffold $\mathbf{1 8}$ to pyrrolidine. The nitrile analog 5a was obtained by coupling 18 with readily available $(S)$-pyrrolidine-2carbonitrile (Scheme 1).

Scheme 1. Synthesis of diversely functionalized inhibitors. ${ }^{\mathrm{a}}$

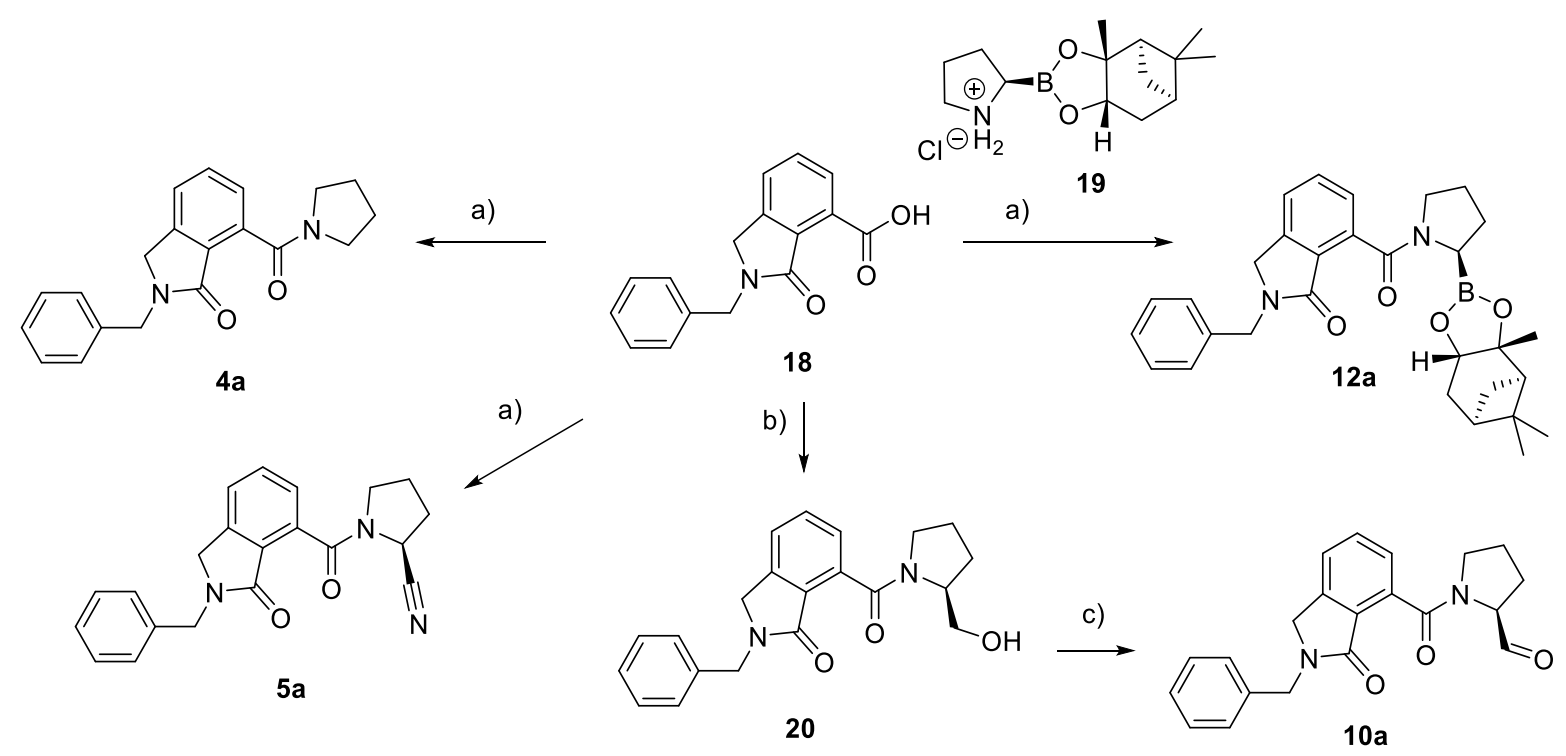

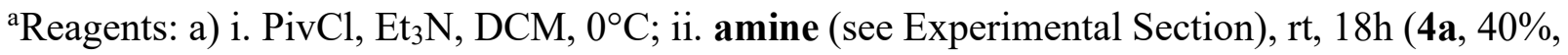
5a, 92\%, 12a, 43\%); b) i. PivCl, $\mathrm{Et}_{3} \mathrm{~N}, \mathrm{DCM}, 0{ }^{\circ} \mathrm{C}$; ii. Prolinol, $18 \mathrm{~h}, \mathrm{rt}(87 \%)$; c) DMSO, Oxalylchloride, $\mathrm{DCM},-78^{\circ} \mathrm{C}(40 \%)$.

Synthesis of the selected fluorocyanopyrrolidine analogues begun from readily available starting materials. ${ }^{23}$ Coupling of $\mathbf{1 8}$ with nitrile 21 led to the corresponding inhibitor 13a. Reaction of readily available free amines 22 and $\mathbf{2 3}$ with the bicycle core $\mathbf{1 8}$ under standard coupling conditions afforded the intended inhibitors 14a and 15a, respectively. The non-covalent inhibitors 16a and 17a were prepared through coupling of carboxylic acid 18 with 24 and 25, respectively. 
Scheme 2. ${ }^{\text {a }}$ Synthesis of the fluorine-containing compounds.

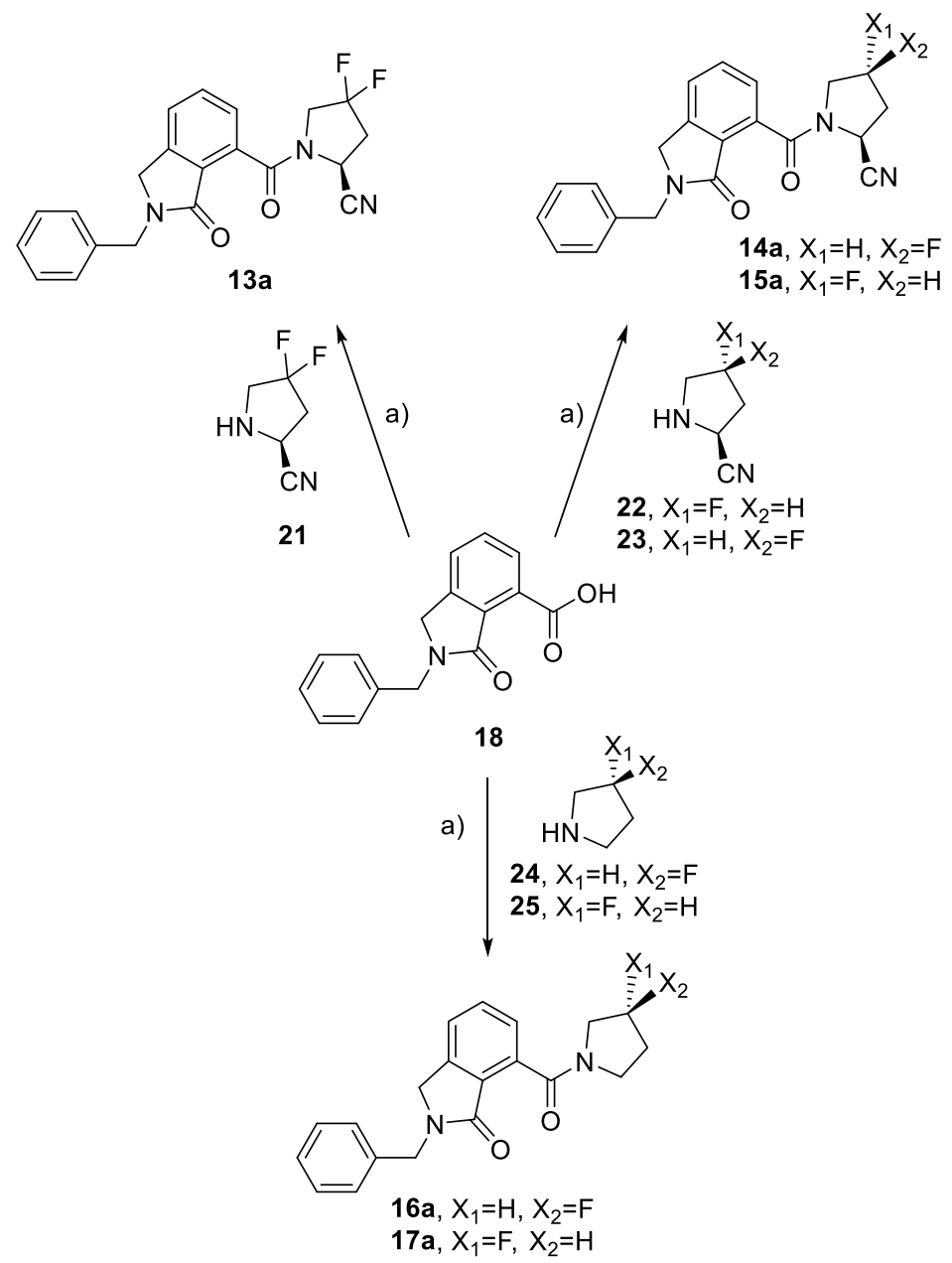

${ }^{a}$ Reagents: a) i. PivCl, Et $3 \mathrm{~N}, \mathrm{DCM}, 0^{\circ} \mathrm{C}$; ii. amine (see Experimental Section), rt, $18 \mathrm{~h}$ (13a, 35\%; 14a, 30\%; 15a, 30\% 16a, 90\%; 17a, 90\%)

\section{Biophysical characterization}

Next, these selected molecules were first evaluated for their inhibitory potency against recombinant human POP (Table 1). As expected, while non-functionalized pyrrolidine derivative 4a exhibited a potency of $160 \mathrm{nM}$, the measured $K_{i}$ values for the nitrile (5a), aldehyde (10a) and boronic ester (12a) derivatives were significantly lower. The high reactivity of aldehydes has often been a major issue for developing safe drugs, even in the discovery of Bortezomib (boronic acid proteasome inhibitor, Figure 1). ${ }^{24,25}$ In contrast, the lower reactivity of boronic acids and nitriles allowed medicinal chemists to use them as warhead in drugs such as Bortezomib and Vildagliptin (nitrile-containing covalent DPP-IV inhibitor, Figure 1). This potency trend followed this reactivity order, with the aldehyde being the most intrinsically reactive electrophile and thus the most potent inhibitor, confirming that intrinsic reactivity is a factor for optimal enzyme inhibition. Figure 6 shows the dose-response curves for covalent inhibitors 10a and 12a. 


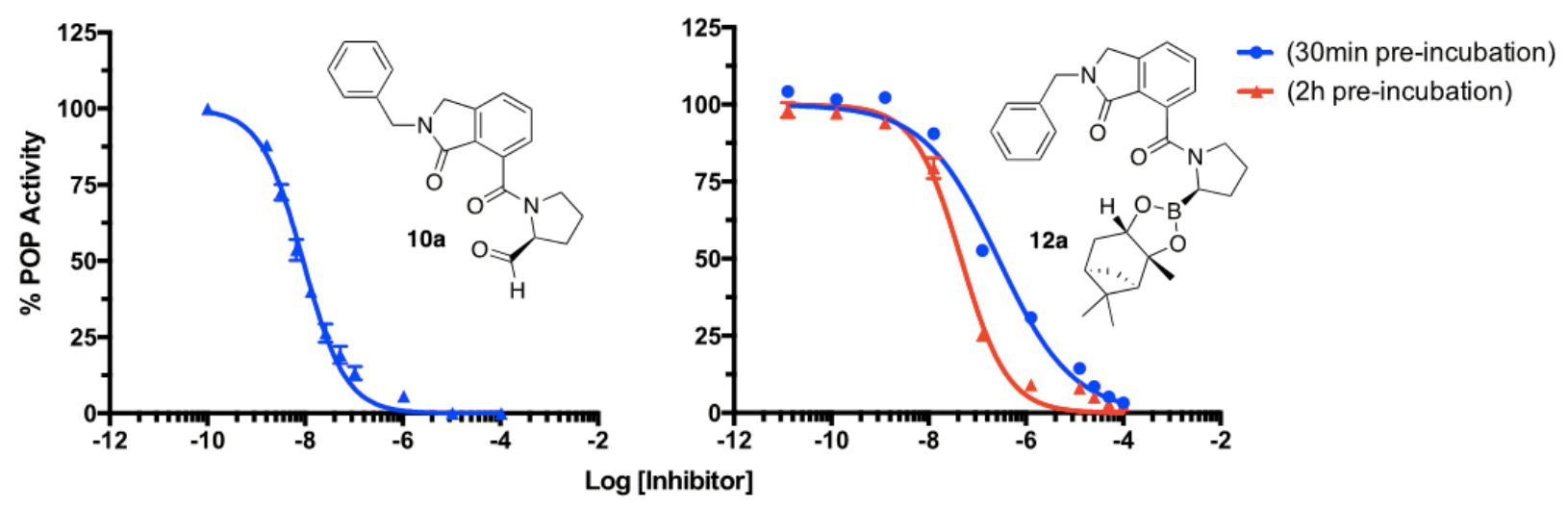

Figure 6. Dose-response curves of 10a (left) and 12a (right) against human recombinant POP after 30-minute pre-incubation periods. Boronic ester 12a was additionally tested with a two-hour preincubation period to allow for in situ hydrolysis of the (+)-pinanediol protecting group.

As an observed effect of kinetic factors, the $K_{i}$ decreases over time until equilibrium is reached. While the nitrile and aldehyde derivatives reached equilibrium after 30 minutes of pre-incubation, the boronic ester 12a required a longer incubation period. This was most likely due to the rate of hydrolysis of the boronic ester to the boronic acid 11a, which is required for enzyme binding. Residence time is largely controlled by binding kinetics of the covalent ligand, illustrating the importance of this property. ${ }^{2,26,27}$ Introduction of fluorine atoms onto the pyrrolidine ring of our lead compound 5a led to complete loss (15a) or a decrease (13a, 14a) in potency. A similar decrease in affinity was also observed for the non-covalent inhibitors bearing a fluorine atom on the pyrrolidine ring (4a vs. 16a and 17a), suggesting that factors other than the nitrile reactivity modulate potency.

Additional biophysical characterization experiments were performed for select inhibitors 10a, 12a, and control 1. To extract kinetic parameters, progress curve experiments were conducted at various inhibitor concentrations. Data from these curves were then used to extract the respective $k_{o b s}$ values, which were further plotted against inhibitor concentration; the resultant data was subsequently fitted to the corresponding equations (see Supporting Information) in order to retrieve the inhibitors' kinetic parameters. Finally, rapid dilution experiments were performed to obtain residence time $t_{R}$. (See Supporting Information for the raw data curves of the abovementioned experiments.) Kinetic parameters of each compound are provided in Table 1. Unfortunately, any attempts to obtain kinetic parameters for the non-covalent, the prolinonitrile, and the fluorinated prolinonitrile derivatives proved unsuccessful, as the off rates were too quick to measure experimentally.

Table 1. Summary of the kinetic parameters measured experimentally.*

\begin{tabular}{llllllll}
\hline Cpd & $K_{i}(\mathrm{nM})^{\mathrm{a}}$ & $K_{i}(\mathrm{nM})^{\mathrm{b}}$ & $K_{i}^{*}(\mathrm{nM})^{\mathrm{c}}$ & $\begin{array}{l}k_{\text {on }} \\
\left(10^{5} \mathrm{M}^{1} \mathrm{~s}^{-1}\right)\end{array}$ & $\begin{array}{l}k_{\text {off }} \\
\left(10^{-4} \mathrm{~s}^{-1}\right)\end{array}$ & $\mathrm{t}_{\mathrm{R}}(\mathrm{min})$ & $\mathrm{FAP}^{\mathrm{d}}$ \\
\hline $\mathbf{1}$ & $1 \pm 0.1$ & $8 \pm 1$ & $0.4 \pm 0.02$ & $7.8 \pm 2.2$ & $3.9 \pm 0.5$ & $42 \pm 5$ & $<5 \%{ }^{28}$ \\
$\mathbf{4 a}$ & $160 \pm 40$ & - & - & - & - & $<1$ & $<5 \%$
\end{tabular}




\begin{tabular}{|c|c|c|c|c|c|c|c|}
\hline $5 a$ & $25 \pm 4$ & - & $25 \pm 4$ & - & - & $<1$ & $20 \%$ \\
\hline $10 \mathbf{a}$ & $4.0 \pm 0.4$ & $20 \pm 9$ & $3.5 \pm 0.2$ & $1.86 \pm 0.7$ & $8.2 \pm 0.2$ & $20 \pm 0.8$ & $80 \%(11 \%)$ \\
\hline $12 a$ & $\begin{array}{l}110 \pm 40^{\mathrm{e}} \\
22 \pm 5^{\mathrm{f}}\end{array}$ & $60 \pm 10$ & $29 \pm 2$ & $0.04 \pm 0.01$ & $2.3 \pm 0.3$ & $73 \pm 10$ & $<5 \%$ \\
\hline $13 a$ & $\begin{array}{l}3,300 \quad \pm \\
780\end{array}$ & - & - & - & - & - & $<5 \%$ \\
\hline $14 a$ & $170 \pm 40$ & - & - & - & - & - & $<5 \%$ \\
\hline $15 a$ & $>100 \mu \mathrm{M}$ & - & - & - & - & - & $<5 \%$ \\
\hline $16 \mathbf{a}$ & $290 \pm 50$ & - & - & - & - & - & $<5 \%$ \\
\hline $17 \mathbf{a}$ & $620 \pm 90$ & - & - & - & - & - & $<5 \%$ \\
\hline
\end{tabular}

\footnotetext{
${ }^{a}$ Affinity constant, measured by absorbance assay. ${ }^{b}$ Affinity constant of the first step of the binding event, measured by dilution experiments. ${ }^{\mathrm{c}}$ Affinity constant of the second step of inhibition. dinhibition at $100 \mu \mathrm{M}($ at $1 \mu \mathrm{M})$. ${ }^{\mathrm{e}} 30$ minute $\mathrm{E}-\mathrm{I}$ pre-incubation time. ${ }^{\mathrm{f}} 2$ hour E-I preincubation time. *missing parameters (-) indicate that the kinetics of the reaction were too quick to measure experimentally
}

\section{Computational study}

To study these kinetic parameters and provide insight into the development of effective prediction methods for covalent inhibitors, the quantum chemical cluster approach (QCCA) ${ }^{29}$ was employed. Starting geometries were taken from crystal structures. The ligands were truncated to focus on energetics of covalent bond formation/breakage while maintaining the electronics of the electrophile (e.g., 10b as a model for 10a). 


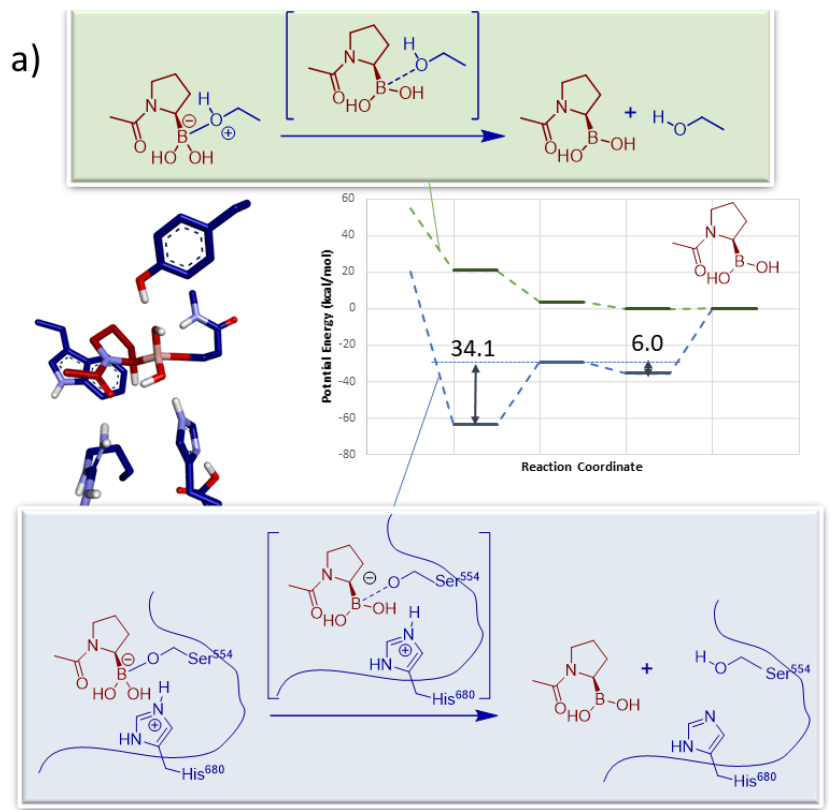

b)

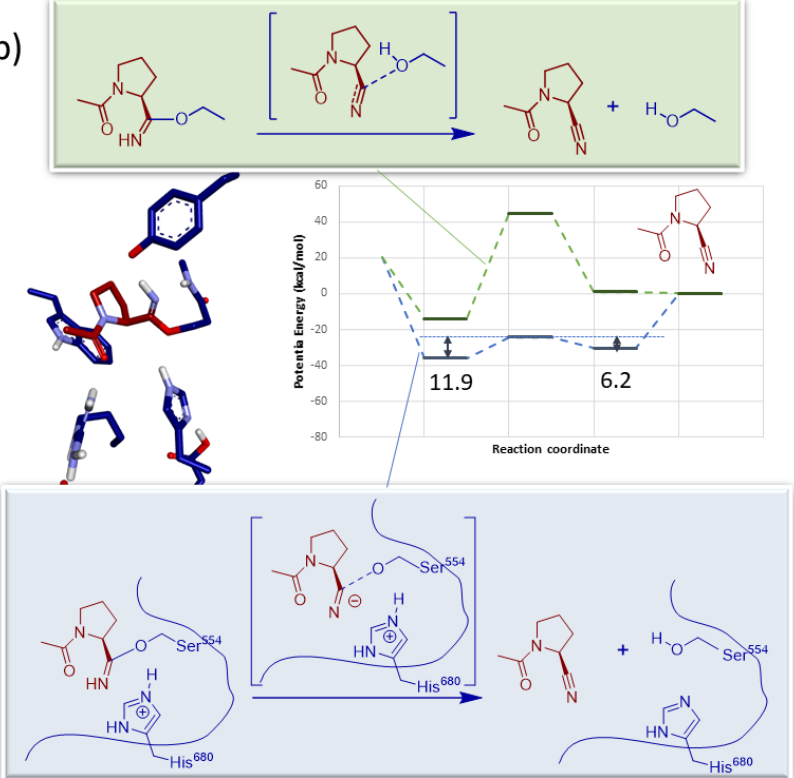

Figure 7. Data collected for boronic acid (a) and nitrile (b) as warhead. In blue is the energy of the enzyme-catalyzed reaction and in green the same reaction with no enzyme. Non-polar hydrogens are omitted for clarity.

As per the QCCA protocol, the binding site was restricted to the catalytic triad residues along with other key residues, such as the backbone of residues contributing to the oxy-anion hole (Figure 5c). The second step of the binding process was then simulated to acquire several thermodynamic and kinetic parameters, such as binding energies and activation energies for binding and unbinding, which together with enzyme mobility and non-bonded interactions contribute to $k_{o n}$ and $k_{\text {off }}$ (Table 2, SI). In order to develop a protocol that would minimize calculation time, we decided to compute the energy at evenly distributed distances only. As a result, the "ideal" distance or transition state distances were not necessarily assessed, only close- 
to-minima structures. Although the search for the energy at the optimal distances is expected to improve accuracy, it is also expected to significantly increase computational time and hence decrease efficiency, as locating a transition state is not a simple task. Rather, our method is expected to provide us with trends which would be accurate enough to make informed decisions on whether a target is covalently druggable. Considering this approximation, we also considered different levels of theory, from semiempirical (AM1) to higher levels (PBE0/def2-TZVP/D3BJ).

Table 2. Summary of the parameters obtained computationally (all values are in $\mathrm{kcal} / \mathrm{mol}$ ).

\begin{tabular}{ccccccccc}
\hline & \multicolumn{2}{c}{$\mathrm{E}_{\text {off }}$} & \multicolumn{2}{c}{$\mathrm{E}_{\text {on }}$} & \multicolumn{2}{c}{$\Delta \mathrm{G}($ cov. - non-cov. $)$} & \multicolumn{2}{c}{ Binding Energy } \\
Cpd. & POP & FAP & POP & FAP & POP & FAP & POP & FAP \\
\hline $\mathbf{5 b}$ & 11.9 & 6.2 & 6.2 & 7.5 & -5.7 & 1.3 & -36.0 & -27.0 \\
$\mathbf{1 0 b}$ & 18.8 & 16.9 & 1.8 & 3.9 & -17.0 & -13.0 & -49.9 & -42.9 \\
$\mathbf{1 1 b}$ & 34.1 & 26.0 & 6.0 & $<1.0^{\mathrm{a}}$ & -28.1 & -26.0 & -63.5 & -55.8 \\
$\mathbf{1 3 b}$ & 14.2 & 12.6 & 8.4 & 5.9 & -5.8 & -6.7 & -37.3 & -29.1 \\
$\mathbf{1 4 b}$ & 9.8 & 5.7 & 8.5 & 10.6 & -1.3 & 4.9 & -34.4 & -25.4 \\
$\mathbf{1 5 b}$ & 13.7 & 10.9 & 6.6 & 10.2 & -7.1 & -0.7 & -39.2 & -32.8 \\
\hline
\end{tabular}

${ }^{\mathrm{a}}$ The compound forms a covalent bond without an energy barrier. ${ }^{\mathrm{b}}$ computed with the pseudo axial conformation (see text).

\section{Discussion}

The computational data suggests that the warhead does in fact have a direct influence on the kinetics and thus activity of the second step in ligand binding. According to this data, the aldehyde and boronic acid are predicted to have longer residence times than any of the nitrile derivatives, represented by significantly larger $E_{\text {off }}$ values. The data also suggested that the nitriles had a slightly higher activation energy $\left(E_{\text {on }}\right)$ in FAP than in POP. More surprisingly, the conversion of the aldehyde to the hemi-acetal and the boronic acid to the boronate in the active site appear to possess a very low energy barrier. This would imply that covalent bond formation is rapid, only limited by diffusion of the ligand into the active site and reorientation of the electrophilic warhead to allow covalent bond formation. This low energy barrier is attributed to two observations: (1) the ligands appear to be pre-activated by Tyr473 as they approach the nucleophilic serine, and (2) the transition states of these reactions resemble the transition state adopted by the natural substrates and are highly stabilized through hydrogen bonding. Interestingly, in the case of nitriles, the proximal Tyr473 hydroxyl group is properly positioned to transfer a proton to the forming imine despite the $\mathrm{sp}^{2}$ character of this intermediate. While ligand-enzyme kinetics were the focus of these computations, we also observed that in the case of the nitrile, energy of the covalently bound state was not necessarily significantly lower than that of the non-covalent complexes, keeping in agreement with low residence time. We next investigated whether computing the full binding process was required. First, we computed the correlation between the binding energies and $\mathrm{E}_{\text {off }}$ for POP (Table 2; Figure S16), according to the Bell-Evans-Polanyi principle. ${ }^{30}$ This principle 
establishes a linear relationship between the activation energy and the enthalpy of reaction in the same family of reactions. The $\mathrm{R}^{2}$ coefficient of 0.96 confirms a significant correlation between the binding energies and $E_{\text {off, }}$ and suggest that future investigations should simply focus on ground states, thus streamlining the process. We next computed theoretical half-lives $\mathrm{t}_{1 / 2}$ of both the initial bond formation as well as the bond breakage (Tables S3 and S4) which are significantly lower than the residence times (Table 2). The bond formation/breaking was significantly faster than the experimental residence time, suggesting that the inhibition process is under thermodynamic control. Thus, the binding energies should also correlate with the experimentally determined $K_{i}$ values. We plotted the relevant graph (Figure S16) and we observed no correlation between the binding energies and $K_{i}$ values $\left(\mathrm{R}^{2}=0.17\right)$. Several factors are responsible for this apparent lack of correlation: first, we computed the binding energies of truncated fragments, while the $K_{i}$ values were determined using the full molecules. While we tried to obtain $K_{i}$ values for the fragments alone, they showed no activity in POP or FAP (data not shown), revealing the critical contribution of the rest of the molecules to the binding affinity. Secondly, the $K_{i}$ values were computed in solution, while our computations were performed exclusively in the gas phase. We believe that for accurate solvent effects an explicit solvent should be used, ${ }^{31}$ which can be reliably done using molecular dynamics simulations. However, this is beyond the scope of our computations, which intend to offer a qualitative analysis and trends with respect to reactive warheads. In addition, the use of small fragments assumes that the warheads are properly positioned to form a reversible covalent bond. Adding groups to these fragments certainly modulates these optimal alignments hence the $K_{i}$. Finally, we observed that association rate of 10a showed a significant temperature dependence, which we attribute to the large conformational rearrangement of POP that accompanies ligand binding, ${ }^{32}$ a motion not considered when computationally binding fragments.

It should be noted that the objective of this research is to define whether a covalent bond is possible (covalent druggability) and which warhead would be optimal but not whether a given molecule is to be a strong inhibitor.

Although the computational trends match the experimental trends, the computed low energy barriers for the aldehyde and boronic acid contrast with the commonly reported slow covalent binding step (Figure 3a). One such disagreement between computations and experiment exists for compound $\mathbf{1 5 a} \mathbf{a} / \mathbf{b}$. A closer look at the models revealed that the preferred conformation (pseudoaxial fluorine) cannot geometrically form the covalent bond and must rearrange into the less energetically favored pseudo-equatorial conformation. We and others have previously found that fluorine atoms have major control on five-membered ring conformations. ${ }^{31}$ This phenomenon was also observed in FAP by Jansen et al., with inhibitors bearing the cis-fluorine as in 14c exhibiting potency two orders of magnitude greater than those bearing the trans-fluorine as in $\mathbf{1 5 c} .^{20}$ Computations of binding energies (from dissociated complexes to covalently bound complexes) suggests that POP binds these fluorinated proline mimics more tightly than FAP. As discussed above, this apparent discrepancy between experimental and computational results stems from the use of ideally positioned fragments used in the computational investigations of the covalent bond formation which experimentally do not inhibit the enzymes vs. the larger molecules used in the in vitro assays.

By means of progress curve analyses and rapid dilution experiments, relevant parameters such as the $K_{i}$ (affinity constant of the non-covalent component of binding), the $K_{i}^{*}$ (affinity of the second step of inhibition), $k_{\text {on }}$ (association rate) and $k_{\text {off }}$ (dissociation rate) were experimentally determined (Table 1, see SI for details). As a control experiment, Cbz-Pro-prolinal (1) was first 
investigated, and the data obtained was in agreement with a previous report. ${ }^{22}$ The results for our designed inhibitors confirmed that the intrinsic reactivity of the warhead of the covalent inhibitor greatly influenced the on- and off-rates of ligand binding. The boronic ester inhibitor (12a) displayed the slowest on-rate of inhibition $\left(k_{o n}\right)$. As discussed above, hydrolysis of the boronic ester was an additional factor in the on-rate of inhibition. ${ }^{33,34}$ Similarly, aldehyde 10a, although displaying significantly faster on-rates than boronic ester 12a, interacted relatively slowly compared to nitrile 5a, where no slow-binding was detected. The relatively slow binding of the aldehyde-containing inhibitor was attributed to the presence of a pre-existing equilibrium in aqueous solution of an active aldehyde form and an inactive hydrate form of the ligand, while no such equilibrium exists with nitriles. While fast binding was predicted when covalent bond formation was computed ( $k_{2}$ in Figure $3 \mathrm{a}$ ), $k_{\text {on }}$ measures the entire two-step process.

In agreement with the computations, aldehydes and boronic acids have the longest residence times. Experimentally, our aldehyde compound 10a has a residence time 20 minutes shorter than that of Cbz-Pro-prolinal (1). In contrast, boronic ester 12a displayed nearly a four-fold longer residence time, rationalized by the additional stabilizing interactions of the resultant boronic acid hydroxyl groups with residues in the active site of POP, as proposed by docking and QM studies (Figures 5b, 5c). Nitrile inhibitor 5a displayed a very short residence time, despite bearing the same scaffold as 12a and 10a, correlating with the low $E_{\text {off }}$ computed in POP. These short residence times may also result from 5a binding non-covalently as suggested by the small difference in energy between covalently bound and non-covalently bound complexes (Table 2). From the experimental data, we can conclude that the nitrile does not provide a strong enough covalent adduct needed to maintain a longer-bound time in POP, which is in agreement with the computations. As discussed above, covalent ligand-protein complexes of both 12a and 10a with POP exhibit a tetrahedral geometry, resembling that of the transition state geometry formed by the enzyme while carrying out its peptidase activity. In contrast, the covalent complex resulting from reaction with nitrile 5a exhibits a trigonal planar geometry (Figure 3d).

The computations suggested that the pre-orientation of the ligand by the tyrosine facilitates rapid bond formation and, coupled to the small activation barrier, that the covalent binding step may be very fast (Figure 7). This prediction is supported by kinetic results we recently obtained for a related scaffold in which addition of a nitrile warhead actually led to a moderate increase in the binding rate compared to the equivalent non-covalent inhibitor. ${ }^{35}$ In contrast, the association rate for the covalent inhibitor would be lower than that of the non-covalent analogue if bond formation were indeed rate-limiting.

The correlation between computations and experiments provides validation for the QCCA method's ability to predict the overall trends in binding kinetics in POP for covalent ligands and gave us confidence in the data for FAP, an enzyme which is extremely difficult to express and handle experimentally. Our computations indicate that the binding of our truncated nitrile ligands to FAP should have greater $\mathrm{E}_{\text {on }}$ and smaller $\mathrm{E}_{\text {off }}$ likely rendering it less active, while the aldehyde and boronic acid remain reactive enough to inhibit the enzyme. This prediction is consistent with our literature survey, which revealed that although many POP inhibitors feature a nitrile, most potent FAP inhibitors feature a boronic acid or an activated nitrile (Figure 1). The computations were also in agreement with our experimental data on FAP inhibitory activity of compound 5a (20\% inhibition at $100 \mu \mathrm{M})$ and compound $10 a(80 \%$ inhibition at $100 \mu \mathrm{M})$, although the large bicyclic core of our inhibitor may also hinder binding to FAP. 


\section{Conclusion}

In conclusion, this study aimed to streamline the investigation of two covalently druggable targets using computational methods to provide a better understanding of experimentally-obtained thermodynamic and kinetic factors involved in their covalent inhibition and to further study the factors controlling general covalent drug potency. With POP, an enzyme which can easily be expressed and purified, experimental and computational data were in excellent agreement and revealed that the commonly held belief that covalent bond formation is rate limiting for covalent inhibitors does not necessarily stand when highly reactive enzyme residues and/or inhibitors are involved. Our validated computational protocol then rationalized the wide use of boronic acids in FAP inhibition versus the more commonly used nitrile in POP inhibition. The results presented here are a first step towards using computational methods to complete a larger study of covalent binding kinetics, a concept which is entirely unaccounted for in current computational prediction tools such as molecular docking. The ability to integrate kinetic data into prediction tools will improve the ability to rank ligands shown to be active.

Our collaborative approach to this model system aims to facilitate future covalent drug discovery endeavors. By applying our computational methods to predict the relative reactivity of a newlydiscovered target's catalytic residue, biologists and chemists can determine whether the target is covalently druggable and therefore more efficiently design the most promising drug candidates. These predictions will, in the long run, save valuable time and resources in the very costly drug discovery and development processes.

\section{Experimental Section. \\ Chemistry}

General information. All commercially available reagents were used without further purification unless otherwise stated. The $4 \AA$ molecular sieves were dried at $100^{\circ} \mathrm{C}$ prior to use. FTIR spectra were recorded using a Perkin-Elmer Spectrum One FT-IR. ${ }^{1} \mathrm{H}$ and ${ }^{13} \mathrm{C}$ NMR spectra were recorded on Varian Mercury $400 \mathrm{MHz}$, Varian $300 \mathrm{MHz}$, Unity $500 \mathrm{MHz}$, Bruker $400 \mathrm{MHz}$, or Bruker $500 \mathrm{MHz}$ spectrometers. Chemical shifts are reported in ppm using the residual of deuterated solvents as internal standard. Thin layer chromatography visualization was performed by UV or by development using $\mathrm{KMnO}_{4}, \mathrm{H}_{2} \mathrm{SO} 4 / \mathrm{MeOH}, \mathrm{Mo} / \mathrm{Ce}, \mathrm{CAM}$ solutions. Chromatography was performed on silica gel 60 (230-40 mesh) or using Biotage Isolera One purification system with ZIP cartridges. Low resolution mass spectrometry was performed by ESI using a Thermoquest Finnigan LCQ Duo. High resolution mass spectrometry was performed by EI peak matching $(70 \mathrm{eV})$ on a Kratos MS25 RFA double focusing mass spectrometer or by ESI on a Ion Spec 7.0 T FTMS at McGill University. Prior to biological testing, reversed phase HPLC was used to verify the purity of compounds on an Agilent 1100 series instrument equipped with VWD-detector, C18 reverse column (Agilent, Zorbax Eclipse XDB-C18 $150 \mathrm{~mm} 4.6 \mathrm{~mm}, 5 \mu \mathrm{m}$ ), $\mathrm{UV}$ detection at $254 \mathrm{~nm}$. Measured purities for all tested compounds are listed in Table $\mathrm{S} 1$ in the Supporting Information.

General Procedure for peptidic coupling. The carboxylic acid $\mathbf{1 8}$ (1 eq) was suspended in anhydrous DCM $(0.1 \mathrm{M})$ under argon atmosphere, and $\mathrm{Et}_{3} \mathrm{~N}(5 \mathrm{eq})$ was added. The resultant solution was cooled to $0^{\circ} \mathrm{C}$, and pivaloyl chloride $(1.1 \mathrm{eq})$ was added. After $1 \mathrm{~h}$ of stirring at $0^{\circ} \mathrm{C}$, the amine (1.1 eq) was added, and the reaction stirred at room temperature overnight. Water was added, and the product was extracted with EtOAc or with DCM (depending on the amount of original DCM solvent). The combined organic layers were washed with $1 \mathrm{M} \mathrm{HCl}$, saturated $\mathrm{NaHCO}_{3}$, and brine, dried over $\mathrm{Na}_{2} \mathrm{SO}_{4}$, filtered, and concentrated in vacuo. The crude residue was 
purified by flash chromatography on a silica gel column to give the product. Residues were triturated in hexanes and/or $\mathrm{Et}_{2} \mathrm{O}$ and filtered under vacuum to give solids.

2-benzyl-7-(pyrrolidine-1-carbonyl)isoindolin-1-one (4a) Compound 4a was synthesized following the general procedure for peptidic coupling, using pyrrolidine as the corresponding amine (40\%). ${ }^{1} \mathrm{H}$ NMR (500 MHz, Chloroform- $d$ ) $\delta 7.52(\mathrm{t}, J=7.6 \mathrm{~Hz}, 1 \mathrm{H}), 7.37$ (dd, $J=7.5,1.7$ $\mathrm{Hz}, 2 \mathrm{H}), 7.34-7.25(\mathrm{~m}, 5 \mathrm{H}), 4.97-4.80(\mathrm{~m}, 1 \mathrm{H}), 4.73-4.50(\mathrm{~m}, 1 \mathrm{H}), 4.24(\mathrm{~s}, 2 \mathrm{H}), 3.92-3.75$ (m, 1H), $3.75-3.59(\mathrm{~m}, 1 \mathrm{H}), 3.42-3.20(\mathrm{~m}, 1 \mathrm{H}), 3.17-2.99(\mathrm{~m}, 1 \mathrm{H}), 2.06-1.73(\mathrm{~m}, 4 \mathrm{H}) ;{ }^{13} \mathrm{C}$ NMR $\left(126 \mathrm{MHz}, \mathrm{CDCl}_{3}\right) \delta$ 24.61, 26.01, 45.70, 46.48, 48.25, 49.33, 77.16, 123.34, 126.22, $127.85,128.28$ (2C), 128.39 (2C), 128.91, 131.80, 135.51, 136.94, 141.76, 166.88, 167.02. Spectral and experimental data previously published by our group. ${ }^{13}$

1-(2-benzyl-3-oxoisoindoline-4-carbonyl)pyrrolidine-2-carbonitrile (5a) Compound 5a was synthesized following the general procedure for peptidic coupling, using $(S)$-pyrrolidine-2carbonitrile pTsOH salt as the corresponding amine (92\%). ${ }^{1} \mathrm{H}$ NMR (400 MHz, Acetone- $\left.d_{6}\right) \delta$ $7.70-7.48(\mathrm{~m}, 2 \mathrm{H}), 7.47-7.38(\mathrm{~m}, 1 \mathrm{H}), 7.37-7.13(\mathrm{~m}, 5 \mathrm{H}), 5.03-4.54(\mathrm{~m}, 3 \mathrm{H}), 4.41(\mathrm{~s}, 2 \mathrm{H})$, $3.79-3.66(\mathrm{~m}, 0.5 \mathrm{H}), 3.38-3.17(\mathrm{~m}, 1.5 \mathrm{H}), 2.48-2.34(\mathrm{~m}, 1 \mathrm{H}), 2.34-2.21(\mathrm{~m}, 1 \mathrm{H}), 2.21-2.07$ $(\mathrm{m}, 1 \mathrm{H}), 2.04-1.96(\mathrm{~m}, 1 \mathrm{H})$; Carbon peaks reported for major rotamer. ${ }^{13} \mathrm{C} \mathrm{NMR}(101 \mathrm{MHz}$, Acetone- $\left.d_{6}\right) \delta 25.75,29.84,31.25,46.56,47.04,48.58,50.05,119.70,125.15,126.83,128.31$, 128.84 (2C), 129.11, 129.55 (2C), 132.54, 134.47, 138.48, 143.32, 167.22, 167.88. Spectral and experimental data previously published by our group. ${ }^{13}$

(S)-2-benzyl-7-(3-fluoropyrrolidine-1-carbonyl)isoindolin-1-one (16a) / (R)-2-benzyl-7-(3fluoropyrrolidine-1-carbonyl)isoindolin-1-one (17a) Compounds 16a/17a were synthesized following the general procedure for peptidic coupling, using 24/25 as the corresponding amines. The crude residues were purified using $100 \%$ EtOAc as the eluent system $(90 \% / 90 \%$, white solids); As they are enantiomers, they gave identical spectral properties. $R_{f} .0 .18$ (100\% EtOAc); IR (film) vmax $\left(\mathrm{cm}^{-1}\right) 3005,1682,1627,1607,1433,1206 ;{ }^{1} \mathrm{H}$ NMR $(500 \mathrm{MHz}$, Chloroform- $d$ ) $\delta$ 7.54 (td, $J=7.5,2.6 \mathrm{~Hz}, 1 \mathrm{H}), 7.40(\mathrm{t}, J=7.5 \mathrm{~Hz}, 2 \mathrm{H}), 7.34-7.22(\mathrm{~m}, 5 \mathrm{H}), 5.26$ (ddt, $J=82.8$, $52.9,3.9 \mathrm{~Hz}, 1 \mathrm{H}), 4.87-4.56(\mathrm{~m}, 2 \mathrm{H}), 4.32-4.19(\mathrm{~m}, 2 \mathrm{H}), 4.15-3.75(\mathrm{~m}, 2 \mathrm{H}), 3.63-3.32(\mathrm{~m}$, $2 \mathrm{H}), 2.46-2.03(\mathrm{~m}, 2 \mathrm{H})$; Carbon peaks reported for both rotamers. ${ }^{13} \mathrm{C} \mathrm{NMR}\left(126 \mathrm{MHz}, \mathrm{CDCl}_{3}\right)$ $\delta 31.20,31.37,32.74,32.91,43.60,45.90,46.47,49.37,52.41,52.60,54.22,54.40,77.16,92.06$ $(\mathrm{d}, J=175.3 \mathrm{~Hz}), 92.80(\mathrm{~d}, \mathrm{~J}=177.7 \mathrm{~Hz}), 123.68,123.75,126.28,126.55,127.86,127.89,128.20$ (2C), 128.31 (2C), 128.34 (2C), 128.90 (2C), 128.92 (2C), 131.87, 131.99, 134.57, 134.59, 136.75, 136.81, 141.76, 141.82, 166.79, 166.83, 167.27, 167.31; HRMS (ESI+): calculated for $\left[\mathrm{C}_{20} \mathrm{H}_{19} \mathrm{FN}_{2} \mathrm{O}_{2}+\mathrm{Na}\right]^{+}, 361.1323$; found, 361.132.

(2S,4S)-1-(2-benzyl-3-oxoisoindoline-4-carbonyl)-4-fluoropyrrolidine-2-carbonitrile (14a) Compound 14a was synthesized following the general procedure for peptidic coupling, using 22 as the corresponding amine. The crude residue was purified using $100 \%$ EtOAc as the eluent system (30\%, white solid); $R_{f}: 0.18$ (100\% EtOAc); IR (film) $v_{\max }\left(\mathrm{cm}^{-1}\right) 3012,2920,1682,1653$, 1605, 1409, 1212; ${ }^{1} \mathrm{H}$ NMR (500 MHz, Chloroform- $\left.d\right) \delta 7.72-7.41(\mathrm{~m}, 3 \mathrm{H}), 7.40-7.20(\mathrm{~m}, 5 \mathrm{H})$, $5.58-5.18(\mathrm{~m}, 1.6 \mathrm{H}), 4.87(\mathrm{dd}, J=18.8,14.9 \mathrm{~Hz}, 1 \mathrm{H}), 4.70-4.52(\mathrm{~m}, 1.4 \mathrm{H}), 4.40-4.20(\mathrm{~m}$, $2 \mathrm{H}), 4.20-4.02(\mathrm{~m}, 1 \mathrm{H}), 3.79-3.45(\mathrm{~m}, 1 \mathrm{H}), 2.78-2.49(\mathrm{~m}, 2 \mathrm{H})$; Carbon peaks reported for both rotamers. ${ }^{13} \mathrm{C}$ NMR $\left(126 \mathrm{MHz}, \mathrm{CDCl}_{3}\right) \delta 36.51,36.67,38.24,38.40,44.97,46.60,46.67$, 47.12 , 49.63, 49.77, 53.18, 53.37, 54.14, 54.33, 77.16, 90.34, 91.32, 91.77, 92.76, 117.93 (2C), 124.53, 124.74, 126.89 (2C), 127.53 (2C), 128.10, 128.15, 128.27 (2C), 128.33 (2C), 129.07 (2C), 129.10 (2C), 132.38, 132.49, 132.66, 132.69, 136.38, 136.47, 141.77 (2C), 166.89, 166.91, 167.64, 167.66; HRMS (ESI+): calculated for $\left[\mathrm{C}_{21} \mathrm{H}_{18} \mathrm{FN}_{3} \mathrm{O}_{2}+\mathrm{H}\right]^{+}, 364.14558$; found, 364.14500. 
(S)-1-(2-benzyl-3-oxoisoindoline-4-carbonyl)-4,4-difluoropyrrolidine-2-carbonitrile (13a) Compound 13a was synthesized following the general procedure for peptidic coupling, using 21 as the corresponding amine. The crude residue was purified using 3:1 EtOAc/hexanes as the eluent system $\left(30 \%\right.$, white solid); $\left(R_{f}=0.53 ; 3: 1 \mathrm{EtOAc} /\right.$ hexanes); IR (film) $v_{\max }\left(\mathrm{cm}^{-1}\right) 2918,2850,1666$, 1604, 1411, 1108; ${ }^{1} \mathrm{H}$ NMR (500 MHz, CDCl3) $\delta 7.75-7.57,(\mathrm{~m}, 2 \mathrm{H}), 7.57-7.45$ (m, 2H), 7.43 $-7.28(\mathrm{~m}, 4 \mathrm{H}), 5.34$ (br s, $0.5 \mathrm{H}), 4.96(\mathrm{~d}, J=14.9 \mathrm{~Hz}, 0.5 \mathrm{H}), 4.89-4.80(\mathrm{~m}, 1 \mathrm{H}), 4.71$ (br s, $0.5 \mathrm{H}), 4.62(\mathrm{~d}, J=14.9 \mathrm{~Hz}, 0.5 \mathrm{H}), 4.41-4.24(\mathrm{~m}, 2.5 \mathrm{H}), 4.17(\mathrm{t}, J=15.1 \mathrm{~Hz}, 0.5 \mathrm{H}), 3.82(\mathrm{br} \mathrm{s}$, $0.5 \mathrm{H}), 3.63$ (br s, $0.5 \mathrm{H}), 3.08-2.89(\mathrm{~m}, 1 \mathrm{H}), 2.83$ (t, J=13.2 Hz, 0.5 H), 2.70 (t, J = 13.2 Hz, $0.5 \mathrm{H})$; Peaks include rotamers. ${ }^{13} \mathrm{C} \mathrm{NMR}\left(101 \mathrm{MHz}, \mathrm{CDCl}_{3}\right) \delta 46.69,49.62,49.79,52.76,53.92$ (t, $J=31.9 \mathrm{~Hz}), 77.16,116.78,124.96,125.13,126.89,127.97,128.14,128.23,128.37$ (2C), 129.11 (2C), 129.15, 131.68, 132.36, 132.79, 136.30, 136.51, 141.93, 167.06, 167.52; HRMS (ESI+): calculated for $\left[\mathrm{C}_{21} \mathrm{H}_{17} \mathrm{~F}_{2} \mathrm{~N}_{3} \mathrm{O}_{2}+\mathrm{H}\right]^{+}$, 382.13616; found, 382.13599.

(2S,4R)-1-(2-benzyl-3-oxoisoindoline-4-carbonyl)-4-fluoropyrrolidine-2-carbonitrile (15) Compound 15a was synthesized following the general procedure for peptidic coupling, using 23 as the corresponding amine. The crude residue was purified using 1:1 EtOAc/hexanes as the eluent system (30\%, white solid); ( $R_{f}=0.1 ; 1: 1$ EtOAc/hexanes); IR (film) $v_{\max }\left(\mathrm{cm}^{-1}\right) 3008,2920,1686$, 1648, 1603, 1413, 1205; ${ }^{1} \mathrm{H}$ NMR (400 MHz, Acetone- $\left.d_{6}\right) \delta 8.38-7.55(\mathrm{~m}, 2 \mathrm{H}), 7.52-7.24(\mathrm{~m}$, $6 \mathrm{H}), 5.36(\mathrm{dt}, J=52.2,3.7 \mathrm{~Hz}, 1 \mathrm{H}), 5.15-4.65(\mathrm{~m}, 3 \mathrm{H}), 4.55-4.17(\mathrm{~m}, 2 \mathrm{H}), 3.96-3.43(\mathrm{~m}, 2 \mathrm{H})$, $2.99-2.83(\mathrm{~m}, 1 \mathrm{H}), 2.75-2.52(\mathrm{~m}, 1 \mathrm{H}) ;{ }^{13} \mathrm{C}$ NMR $(101 \mathrm{MHz}$, Acetone) $\delta 29.84,37.61(\mathrm{~d}, J=$ $22.3 \mathrm{~Hz}), 45.37,46.59,49.99,54.93(\mathrm{~d}, J=22.1 \mathrm{~Hz}), 88.77(\mathrm{~d}, J=177.5 \mathrm{~Hz}) 118.79,125.61$, 127.79, 128.31, 128.87, 129.56 (4C), 132.52, 133.90, 138.53, 143.46, 166.90, 167.78; HRMS (ESI+): calculated for $\left[\mathrm{C}_{21} \mathrm{H}_{18} \mathrm{~F}_{1} \mathrm{~N}_{3} \mathrm{O}_{2}+\mathrm{H}\right]^{+}, 364.14558 .{ }^{* 13} C-F$ peak suppressed, HSQC provided as Supporting Information.

(S)-2-benzyl-7-(2-(hydroxymethyl)pyrrolidine-1-carbonyl)isoindolin-1-one

(20). Compound 20 was synthesized following the general procedure for peptidic coupling, using Lprolinol as the corresponding amine. The crude residue was purified using $100 \%$ EtOAc as the eluent system (87\%, white solid); $\left(R_{f}=0.15 ; 100 \%\right.$ EtOAc); IR (film) $v_{\max }\left(\mathrm{cm}^{-1}\right) 3434,2943$, 1671, 1624, 1602, 1432; ${ }^{1} \mathrm{H}$ NMR (500 MHz, Chloroform- $d$ ) $\delta 7.56(\mathrm{t}, J=7.6 \mathrm{~Hz}, 1 \mathrm{H}), 7.42(\mathrm{t}, J$ $=8.0 \mathrm{~Hz}, 2 \mathrm{H}), 7.36-7.31(\mathrm{~m}, 2 \mathrm{H}), 7.31-7.25(\mathrm{~m}, 3 \mathrm{H}), 4.91-4.76(\mathrm{~m}, 2 \mathrm{H}), 4.74-4.59(\mathrm{~m}, 2 \mathrm{H})$, $4.35(\mathrm{t}, J=7.7 \mathrm{~Hz}, 1 \mathrm{H}), 4.33-4.22(\mathrm{~m}, 2 \mathrm{H}), 3.50(\mathrm{t}, J=11.2 \mathrm{~Hz}, 1 \mathrm{H}), 3.29(\mathrm{td}, J=9.7,6.8 \mathrm{~Hz}$, $1 \mathrm{H}), 3.13$ (ddd, $J=10.7,7.8,3.5 \mathrm{~Hz}, 1 \mathrm{H}), 2.26-2.15(\mathrm{~m}, 1 \mathrm{H}), 2.16-2.08(\mathrm{~m}, 1 \mathrm{H}), 2.04-1.93$ $(\mathrm{m}, 1 \mathrm{H}), 1.82-1.69(\mathrm{~m}, 1 \mathrm{H}) ;{ }^{13} \mathrm{C}$ NMR $(126 \mathrm{MHz}$, Chloroform-d) $\delta$ 25.09, 27.56, 46.56, 49.30, 50.08, 59.46, 62.21, 77.16, 123.61, 125.90, 127.78, 127.91, 128.36 (2C), 128.93 (2C), 132.07, 135.46, 136.57, 141.90, 166.51, 167.01; HRMS (ESI+): calculated for $\left[\mathrm{C}_{21} \mathrm{H}_{22} \mathrm{~N}_{2} \mathrm{O}_{3}+\mathrm{Na}\right]^{+}$, 373.15226 ; found, 373.15174 .

2-benzyl-7-((R)-2-((3aR,4R,6R,7a $S)-3 a, 5,5-t r i m e t h y l h e x a h y d r o-4,6-$

methanobenzo $[d][1,3,2]$ dioxaborol-2-yl)pyrrolidine-1-carbonyl)isoindolin-1-one (12a). Compound 12 was synthesized following the general procedure for peptidic coupling, using 19 as the corresponding amine. The crude residue was purified using (1:1 EtOAc/hexanes) as the eluent system (43\%, white foam); IR (film) $v_{\max }\left(\mathrm{cm}^{-1}\right) 3225,2922,1686,1606,1451$; Peaks and coupling constants reported for major rotamer. Full integrated proton spectrum provided. ${ }^{1} \mathrm{H}$ NMR $(500$ $\mathrm{MHz}$, Chloroform- $d) \delta 7.52(\mathrm{t}, J=7.6 \mathrm{~Hz}, 1 \mathrm{H}), 7.42(\mathrm{~d}, J=7.5 \mathrm{~Hz}, 1 \mathrm{H}), 7.37(\mathrm{~d}, J=7.6 \mathrm{~Hz}, 1 \mathrm{H})$, $7.35-7.26(\mathrm{~m}, 5 \mathrm{H}), 4.84(\mathrm{~d}, J=14.8 \mathrm{~Hz}, 1 \mathrm{H}), 4.68(\mathrm{~d}, J=14.8 \mathrm{~Hz}, 1 \mathrm{H}), 4.39(\mathrm{dd}, J=8.9,2.2 \mathrm{~Hz}$, $1 \mathrm{H}), 4.25-4.19(\mathrm{~m}, 2 \mathrm{H}), 3.47(\mathrm{dt}, J=9.2,6.3 \mathrm{~Hz}, 1 \mathrm{H}), 3.42-3.31(\mathrm{~m}, 1 \mathrm{H}), 3.22(\mathrm{dd}, J=17.3$, $7.9 \mathrm{~Hz}, 1 \mathrm{H}), 2.41-2.12(\mathrm{~m}, 3 \mathrm{H}), 2.09(\mathrm{t}, J=5.5 \mathrm{~Hz}, 1 \mathrm{H}), 2.01-1.85(\mathrm{~m}, 5 \mathrm{H}), 1.61(\mathrm{~d}, J=10.9$ $\mathrm{Hz}, 1 \mathrm{H}), 1.45$ (s, 3H), 1.29 (s, 3H), $\left.0.86(\mathrm{~s}, 3 \mathrm{H}) ;{ }^{13} \mathrm{C} \mathrm{NMR} \mathrm{(126} \mathrm{MHz,} \mathrm{CDCl}_{3}\right) \delta 24.28,26.43$, 
$27.29,27.30,27.33,28.92,35.82,38.39,39.79,44.60,46.53,48.15,49.31,51.57,77.16,78.08$, 86.04, 123.60, 127.03, 127.84, 128.42 (2C), 128.67, 128.92 (2C), 128.95, 131.65, 137.08, 141.75, 166.58, 166.69; ${ }^{11} \mathrm{~B}$ NMR $\left(161 \mathrm{MHz}, \mathrm{CDCl}_{3}\right) \delta$ 32.45; HRMS (ESI+): calculated for $\left[\mathrm{C}_{30} \mathrm{H}_{35} \mathrm{~B}_{1} \mathrm{~N}_{2} \mathrm{O}_{4}+\mathrm{H}\right]^{+}$, 499.27736; found, 499.27634.

(S)-1-(2-benzyl-3-oxoisoindoline-4-carbonyl)pyrrolidine-2-carbaldehyde (10a). Oxalyl chloride (108 mg, $1.2 \mathrm{eq})$ was dissolved in DCM $(3 \mathrm{~mL})$, and the solution was cooled to $-78^{\circ} \mathrm{C}$. DMSO (139 mg, $2.5 \mathrm{eq}$, in DCM, $2 \mathrm{~mL}$ ) was added dropwise, and the solution stirred for 2 minutes. 20 (250 mg, $1 \mathrm{eq}$, in $2 \mathrm{~mL}$ DCM) was added dropwise, and the solution stirred for 15 minutes. $\mathrm{Et}_{3} \mathrm{~N}$ (361 mg, $5 \mathrm{eq}$ ) was added, and the solution stirred $15 \mathrm{mins}$. Water was added, and the mixture was warmed to room temperature. The product was extracted with EtOAc, and the combined organic layers were washed with brine, dried over $\mathrm{Na}_{2} \mathrm{SO}_{4}$, filtered, and concentrated in vacuo to give an orange oil, which was purified by flash chromatography on a silica gel column (eluent $100 \%$ EtOAc) to give the product as a white solid (100 mg, 40\%). R.f. 0.30 (100\% EtOAc); IR (film) $v_{\max }\left(\mathrm{cm}^{-1}\right) 3387,3006,1675,1626,1601,1434 ;{ }^{1} \mathrm{H}$ NMR $\left(500 \mathrm{MHz}\right.$, Acetone- $\left.d_{6}\right) \delta 10.13$ - $9.17(\mathrm{~m}, 1 \mathrm{H}), 7.76-7.20(\mathrm{~m}, 8 \mathrm{H}), 4.94-4.58(\mathrm{~m}, 2 \mathrm{H}), 4.56-4.18(\mathrm{~m}, 3 \mathrm{H}), 3.91-3.11(\mathrm{~m}$, $2 \mathrm{H}), 2.29-2.09(\mathrm{~m}, 1 \mathrm{H}), 2.02-1.76(\mathrm{~m}, 3 \mathrm{H}) ;{ }^{13}$ C peaks reported for the major rotamer. ${ }^{13} \mathrm{C} \mathrm{NMR}$ (126 MHz, Acetone) $\delta$ 14.50, 20.83, 23.27, 26.05, 27.59, 29.84, 32.28, 46.56, 49.28, 50.01, 60.53, 65.74, 124.86, 126.43, 128.31, 128.83 (2C), 129.54 (2C), 129.56, 132.49, 135.22, 138.54, 143.36, 167.38, 167.98, 170.88, 202.63; HRMS (ESI+): calculated for $\left[\mathrm{C}_{21} \mathrm{H}_{20} \mathrm{~N}_{2} \mathrm{O}_{3}+\mathrm{H}\right]^{+}, 349.15467$; found, 349.15418.

Biological assays and biophysical characterization.

FAP Assay. The FAP assay was performed using the FAP Assay Kit from BPS BioScience. ${ }^{36}$

POP Protein Expression. POP was expressed and purified according to a procedure previously described. ${ }^{37}$

POP Activity Assays. ZGP-pNA was obtained from Bachem (Bubendorf, Switzerland). $\mathrm{IC}_{50} /$ $K_{i}$ measurements were carried out as follows. The reactions were performed in micro titer plates of 96 wells. For each reaction, activity buffer (A.B.) $(140 \mu \mathrm{L}$, sodium phosphate $20 \mathrm{mM}, \mathrm{NaCl}$ $150 \mathrm{mM}, \beta$-mercaptoethanol $5 \mathrm{mM}$, EDTA $2 \mathrm{mM}, 10 \%$ glycerol, $0.5 \mathrm{mg} / \mathrm{mL} \mathrm{BSA}, \mathrm{pH}=8$ ) was pre-incubated for $30 \mathrm{~min}$ at $30^{\circ} \mathrm{C}$ with hPOP $(20 \mu \mathrm{L}, 10 \mathrm{nM}$ in A.B., final concentration of $1 \mathrm{nM})$ and with the corresponding inhibitor solution $(20 \mu \mathrm{L})$ or activity buffer (controls). Stock inhibitors were prepared in DMSO $(100 \mathrm{mM})$; dilutions for inhibitor evaluation were prepared from the stock in activity buffer. A control experiment with the same DMSO concentration was performed. After pre-incubation, ZGP-pNA $(20 \mu \mathrm{L}, 0.8 \mathrm{mM}$ in A.B., final concentration of $80 \mu \mathrm{M})$ was added and formation of the product was followed by absorbance at $405 \mathrm{~nm}$ every $30 \mathrm{sec}$. Initial velocity was measured for each concentration of inhibitor and compared to the initial velocity of reactions that did not contain inhibitor. The $\mathrm{IC}_{50}$ value was defined as the inhibitor concentration causing a 50 $\%$ decrease in activity. The $K_{\mathrm{i}}$ was defined as $\mathrm{IC}_{50} /\left(1+\left([\mathrm{S}] / K_{\mathrm{m}}\right)\right) . \mathrm{K}_{\mathrm{m}}$ of the substrate has been measured by monitoring the initial velocity of the enzymatic reaction of $1 \mathrm{nM}$ of hPOP with various concentrations of substrate. Data obtained were: $\mathrm{K}_{\mathrm{m}}=74.6 \mu \mathrm{M} ; \mathrm{k}_{\text {cat }}=20.56 \mathrm{~s}^{-1}$.

Progress curves. The reactions were performed in micro titer plates of 96 wells. For each reaction, $140 \mu \mathrm{L}$ of activity buffer was added, followed by $20 \mu \mathrm{L}$ of hPOP (10 nM in A.B.). After $15 \mathrm{~min}$ of equilibration at $30^{\circ} \mathrm{C}, 20 \mu \mathrm{L}$ of inhibitor solution was added (different concentrations were prepared by serial dilution from an original $0.1 \mathrm{M}$ stock in DMSO that was kept at $-80{ }^{\circ} \mathrm{C}$ ). Directly afterwards, $20 \mu \mathrm{L}$ of a $800 \mu \mathrm{M}$ substrate solution (30\% MeCN in activity buffer). Once substrate was added, the absorbance at $405 \mathrm{~nm}$ was recorded every $30 \mathrm{sec}$. during a period of time ranging from $2 \mathrm{~h}$ to $5 \mathrm{~h}$ depending on the inhibitor. Data were then fitted to the corresponding 
equations (see Supporting Information) in order to extract $\mathrm{k}_{\text {obs. }}$ These values were further plotted against inhibitor concentration used and the data fitted to the corresponding equations (see Supporting Information) in order to retrieve kinetic parameters.

Dilution experiment. Inhibitor at a concentration of $100 \mathrm{xKi}$ was pre-incubated with $200 \mathrm{nM}$ of $\mathrm{hPOP}$ in activity buffer for $2 \mathrm{~h}$ at $30^{\circ} \mathrm{C}$. Rapid serial dilutions (two times 40 -fold dilution for a total of 1600-fold) were made with a substrate-containing buffer (Substrate concentration $=80$ $\mu \mathrm{M})$ pre-equilibrated at $30{ }^{\circ} \mathrm{C}$. Final concentrations of inhibitor were $0.06 \mathrm{xKi}$ and the concentration of enzyme was $0.125 \mathrm{nM}$. The absorbance at $405 \mathrm{~nm}$ was immediately recorded every $30 \mathrm{sec}$ for the first 60 minutes followed by every 2 minutes for the next 5 hours. Data were then fitted to the corresponding equations (see Supporting Information) in order to extract $\mathrm{k}_{\text {off. }}$

\section{Computational Chemistry.}

Preparation of the initial systems. The crystal structures for POP and FAP - 2xdw (POP bound to an aldehyde-containing inhibitor), 4an0 (POP bound to a nitrile-containing inhibitor), $4 \mathrm{bcb}$ (POP bound to a nitrile-containing inhibitor) and 1z68 (FAP unbound) were downloaded from the PDB. The six ligands $(\mathbf{5 b}, \mathbf{1 0 b}, \mathbf{1 1 b}, \mathbf{1 3 b}-\mathbf{1 5 b})$ were docked covalently to $2 \mathrm{xdw}$ and $1 \mathrm{z} 68$ using our docking program FITTED. ${ }^{38}$ These crystal structures and docked poses were used to build starting structures. For example, docked poses in POP are similar to the crystal structure with the proline ring properly positioned. However, the stereochemistry of the acetal (from 10b) and the orientation of the iminoether (from $\mathbf{5 b}$ ) are inexact and are repositioned to generate starting structures. Then the FAP structure (1z68) was superposed onto POP (2xdw) and the ligands added to FAP as docked in POP. Considering the rigidity of the aldehyde-containing small molecule and the similarity between the FAP and POP catalytic triad and oxy-anion hole, the binding mode is very likely similar.

The proteins were next truncated; the starting structures are provided as xyz coordinates (mol2 format). For POP the following residues were kept: Asp149, Tyr473, Ser554, Asn555 (backbone NH), Trp595, Asp641, Arg643 and His680; for FAP: Arg123, Glu203, Tyr541, Ser624, Tyr625 (backbone NH), Tyr656, Asp702 and His734. To ensure that all the hot spots are removed, the systems were relaxed according to the following procedure:

- Hydrogens were optimized (AM1) with all heavy atoms frozen.

- The inhibitors were optimized (AM1) with all the protein heavy atoms frozen.

- The complexes were optimized (PBE0/def2-SVP) with only the $\alpha$ and $\beta$ carbons of the amino acids frozen (quantum chemical cluster approach).

Potential energy surface scans. One dimensional potential energy surface (PES) scans were performed in ORCA v.4.0.1.2 $2^{39}$ at the PBE0/def2-SVP level of theory on the optimized structures obtained as described above. The coordinate for the scans was the $\operatorname{Ser}(\mathrm{O})$-warhead(C) distance 13 points were recorded for each scan. For each system the $\alpha$ and $\beta$ carbons of the amino acids were frozen, while the remaining atoms were allowed to move freely. For each system the bound minima, the maxima (if applicable) and the unbound minima were subjected to single point energy calculations at the PBE0/D3BJ/def2-TZVP level of theory. To simulate the unbound states, optimizations were carried on the separate partners (truncated proteins and ligands) at the PBE0/def2-SVP level of theory. Single point energies calculations were then performed on the separated partners in gas phase at the PBE0/def2-TZVP/D3BJ level of theory.

\section{ASSOCIATED CONTENT}


Supporting Information. The following files are available free of charge.

NMR spectra; table of purities for biologically tested compounds; curves and equations corresponding to biological data; computational methods (PDF)

\section{AUTHOR INFORMATION}

\section{Corresponding Author}

\$These authors contributed equally. ${ }^{*}$ Contact information for the author to whom correspondence should be addressed. E-mail: nicolas.moitessier@mcgill.ca

\section{Present Addresses}

$\dagger$ Present Addresses: Stéphane De Cesco, NDM Research Building, Old road campus, University of Oxford, Roosevelt Drive, OX3 7FZ, Oxford, UK

\section{Author Contributions}

The manuscript was written through contributions of all authors. All authors have given approval to the final version of the manuscript. $\$$ These authors contributed equally.

\section{Funding Sources}

This research was financially supported by CIHR through an Operating Grant to NM and AKM (MOP 136943). JP was supported by a McGill University Molson and Hilton Hart Fellowship in Science, SDC was supported by an FRQ-NT scholarship.

\section{Notes}

Any additional relevant notes should be placed here.

\section{ACKNOWLEDGMENT}

We thank CIHR for financial support through an operating grant to NM and AKM (MOP 136943). JP thanks the faculty of science for a McGill University Molson and Hilton Hart Fellowship in Science and SDC thanks the Fonds de Recherche du Quebec, Nature et Technologie for a scholarship

\section{ABBREVIATIONS}

\section{REFERENCES}

(1) Bauer, R. A. Covalent inhibitors in drug discovery: from accidental discoveries to avoided liabilities and designed therapies. Drug Discov. Today 2015, 20, 1061-1073.

(2) Singh, J.; Petter, R. C.; Baillie, T. A.; Whitty, A. The resurgence of covalent drugs. Nat. Rev. Drug Discov. 2011, 10, 307-317.

(3) De Cesco, S.; Kurian, J.; Dufresne, C.; Mittermaier, A. K.; Moitessier, N. Covalent inhibitors design and discovery. Eur. J. Med. Chem. 2017, 138, 96-114.

(4) Powers, J. C.; Asgian, J. L.; Ekici, Ö. D.; James, K. E. Irreversible Inhibitors of Serine, Cysteine, and Threonine Proteases. Chem. Rev. 2002, 102, 4639-4750. 
(5) Szeltner, Z.; Polgar, L. Structure, function and biological relevance of prolyl oligopeptidase. Current Prot. Pept. Sci. 2008, 9, 96-107

(6) Mannisto, P. T.; Vanalainen, J.; Jalkanen, A.; Garcia-Horsman, J. A. Prolyl oligopeptidase: A potential target for the treatment of cognitive disorders. Drug News Perspect 2007, 20, 293-305.

(7) Brandt, I.; Scharpe, S.; Lambeir, A. M. Suggested functions for prolyl oligopeptidase: A puzzling paradox. Clin. Chim. Acta 2007, 377, 50-61.

(8) Lawandi, J.; Gerber-Lemaire, S.; Juillerat-Jeanneret, L.; Moitessier, N. Inhibitors of prolyl oligopeptidases for the therapy of human diseases: Defining diseases and inhibitors. $J$. Med. Chem. 2010, 53, 3423-3438

(9) Santos, A. M.; Jung, J.; Aziz, N.; Kissil, J. L.; Puré, E. Targeting fibroblast activation protein inhibits tumor stromagenesis and growth in mice. J. Clin. Invest. 2009, 119, 3613-3625.

(10) Liao, D.; Luo, Y.; Markowitz, D.; Xiang, R.; Reisfeld, R. A. Cancer associated fibroblasts promote tumor growth and metastasis by modulating the tumor immune microenvironment in a 4T1 murine breast cancer model. PLOS ONE 2009, 4.

(11) Hamson, E. J.; Keane, F. M.; Tholen, S.; Schilling, O.; Gorrell, M. D. Understanding fibroblast activation protein (FAP): Substrates, activities, expression and targeting for cancer therapy. Proteomics Clin. Appl. 2014, 8, 454-463.

(12) Teichgra, V.; Monasterio, C.; Chaitanya, K.; Boger, R.; Gordon, K.; Dieterle, T.; Jager, D.; Bauer, S. Specific inhibition of fibroblast activation protein (FAP)-alpha prevents tumor progression in vitro. Adv. Med. Sci. 2015, 60, 264-272.

(13) De Cesco, S.; Deslandes, S.; Therrien, E.; Levan, D.; Cueto, M.; Schmidt, R.; Cantin, L. D.; Mittermaier, A.; Juillerat-Jeanneret, L.; Moitessier, N. Virtual screening and computational optimization for the discovery of covalent prolyl oligopeptidase inhibitors with activity in human cells. J. Med. Chem. 2012, 55, 6306-6315.

(14) Jöst, C.; Nitsche, C.; Scholz, T.; Roux, L.; Klein, C. D. Promiscuity and Selectivity in Covalent Enzyme Inhibition: A Systematic Study of Electrophilic Fragments. J. Med. Chem. 2014, 57, 7590-7599.

(15) Potashman, M. H.; Duggan, M. E. Covalent Modifiers: An Orthogonal Approach to Drug Design. J. Med. Chem. 2009, 52, 1231-1246.

(16) Flanagan, M. E.; Abramite, J. A.; Anderson, D. P.; Aulabaugh, A.; Dahal, U. P.; Gilbert, A. M.; Li, C.; Montgomery, J.; Oppenheimer, S. R.; Ryder, T.; Schuff, B. P.; Uccello, D. P.; Walker, G. S.; Wu, Y.; Brown, M. F.; Chen, J. M.; Hayward, M. M.; Noe, M. C.; Obach, R. S.; Philippe, L.; Shanmugasundaram, V.; Shapiro, M. J.; Starr, J.; Stroh, J.; Che, Y. Chemical and Computational Methods for the Characterization of Covalent Reactive Groups for the Prospective Design of Irreversible Inhibitors. J. Med. Chem. 2014, 57, 10072-10079.

(17) Zhao, Z.; Liu, Q.; Bliven, S.; Xie, L.; Bourne, P. E. Determining Cysteines Available for Covalent Inhibition Across the Human Kinome. J. Med. Chem. 2017, 60, 2879-2889.

(18) Szeltner, Z.; Rea, D.; Renner, V.; Fulop, V.; Polgar, L. Electrostatic effects and binding determinants in the catalysis of prolyl oligopeptidase. Site specific mutagenesis at the oxyanion binding site. $J$ Biol Chem 2002, 277, 42613-42622.

(19) Kaszuba, K.; Rog, T.; Danne, R.; Canning, P.; Fulop, V.; Juhasz, T.; Szeltner, Z.; St Pierre, J. F.; Garcia-Horsman, A.; Mannisto, P. T.; Karttunen, M.; Hokkanen, J.; Bunker, A. Molecular dynamics, crystallography and mutagenesis studies on the substrate gating mechanism of prolyl oligopeptidase. Biochimie 2012, 94, 1398-1411. 
(20) Jansen, K.; Heirbaut, L.; Verkerk, R.; Cheng, J. D.; Joossens, J.; Cos, P.; Maes, L.; Lambeir, A. M.; De Meester, I.; Augustyns, K.; Van der Veken, P. Extended structure-activity relationship and pharmacokinetic investigation of (4-quinolinoyl)glycyl-2-cyanopyrrolidine inhibitors of fibroblast activation protein (FAP). J. Med. Chem. 2014, 57, 3053-3074.

(21) Smoum, R.; Rubinstein, A.; Dembitsky, V. M.; Srebnik, M. Boron Containing Compounds as Protease Inhibitors. Chem. Rev. 2012, 112, 4156-4220.

(22) Bakker, A. V.; Jung, S.; Spencer, R. W.; Vinick, F. J.; Faraci, W. S. Slow tightbinding inhibition of prolyl endopeptidase by benzyloxycarbonyl-prolyl-prolinal. Biochem J1990, 271, 559-562.

(23) Fukushima, H.; Hiratate, A.; Takahashi, M.; Saito, M.; Munetomo, E.; Kitano, K.; Saito, H.; Takaoka, Y.; Yamamoto, K. Synthesis and structure-activity relationships of potent 3or 4-substituted-2-cyanopyrrolidine dipeptidyl peptidase IV inhibitors. Bioorg Med Chem 2004, $12,6053-6061$.

(24) Nelson, M.-A. M.; Baba, S. P.; Anderson, E. J. Biogenic Aldehydes as Therapeutic Targets for Cardiovascular Disease. Curr. Opin. Pharmacol. 2017, 33, 56-63.

(25) Adams, J. The development of proteasome inhibitors as anticancer drugs. Cancer Cell 2003, 5, 417-421.

(26) Copeland, R. A. The drug-target residence time model: a 10-year retrospective. Nat. Rev. Drug Discov. 2016, 15, 87-95.

(27) Copeland, R. A.; Pompliano, D. L.; Meek, T. D. Drug-target residence time and its implications for lead optimization. Nat. Rev. Drug Discov. 2006, 5, 730-739.

(28) Jambunathan, K.; Watson, D. S.; Endsley, A. N.; Kodukula, K.; Galande, A. K. Comparative analysis of the substrate preferences of two post-proline cleaving endopeptidases, prolyl oligopeptidase and fibroblast activation protein $\alpha$. FEBS lett. 2012, 586, 2507-2512.

(29) Siegbahn, P. E. M.; Himo, F. The quantum chemical cluster approach for modeling enzyme reactions. Wiley Interdiscip. Rev. Comput. Mol. Sci. 2011, 1, 323-336.

(30) Evans, M. G.; Polanyi, M. Further considerations on the thermodynamics of chemical equilibria and reaction rates. J. Chem. Soc. Trans. Faraday Soc. 1936, 32, 1333-1360.

(31) Burai Patrascu, M.; Malek-Adamian, E.; Damha, M. J.; Moitessier, N. Accurately Modeling the Conformational Preferences of Nucleosides. J. Am. Chem. Soc. 2017, 139, 1362013623.

(32) López, A.; Herranz-Trillo, F.; Kotev, M.; Gairí, M.; Guallar, V.; Bernadó, P.; Millet, O.; Tarragó, T.; Giralt, E. Active-Site-Directed Inhibitors of Prolyl Oligopeptidase Abolish Its Conformational Dynamics. ChemBioChem 2016, 17, 913-917.

(33) Kettner, C. A.; Shenvi, A. B. Inhibition of the serine proteases leukocyte elastase, pancreatic elastase, cathepsin G, and chymotrypsin by peptide boronic acids. J. Biol. Chem. 1984, 259, 15106-15114.

(34) Snow, R. J.; Bachovchin, W. W.; Barton, R. W.; Campbell, S. J.; Coutts, S. J.; Freeman, D. M.; Gutheil, W. G.; Kelly, T. A.; Kennedy, C. A. Studies on Proline Boronic Acid Dipeptide Inhibitors of Dipeptidyl Peptidase IV: Identification of a Cyclic Species Containing a B-N Bond. J. Am. Chem. Soc. 1994, 116, 10860-10869.

(35) Di Trani, J. M.; De Cesco, S.; O'Leary, R.; Plescia, J.; do Nascimento, C. J.; Moitessier, N.; Mittermaier, A. K. Rapid measurement of inhibitor binding kinetics by isothermal titration calorimetry. Nat. Commun. 2018, 9, 893.

(36) FAP Assay Kit. http://bpsbioscience.com/fluorogenic-fap-assay-kit-80210 (accessed 29 Aug 2017). 
(37) Mariaule, G.; De Cesco, S.; Airaghi, F.; Kurian, J.; Schiavini, P.; Rocheleau, S.; Huskic, I.; Auclair, K.; Mittermaier, A.; Moitessier, N. 3-Oxo-hexahydro-1H-isoindole-4carboxylic Acid as a Drug Chiral Bicyclic Scaffold: Structure-Based Design and Preparation of Conformationally Constrained Covalent and Noncovalent Prolyl Oligopeptidase Inhibitors. JMed Chem 2016, 59, 4221-4234.

(38) Moitessier, N.; Pottel, J.; Therrien, E.; Englebienne, P.; Liu, Z.; Tomberg, A.; Corbeil, C. R. Medicinal Chemistry Projects Requiring Imaginative Structure-Based Drug Design Methods. Acc. Chem. Res. 2016, 49, 1646-1657.

(39) Neese, F. Software update: the ORCA program system, version 4.0. Wiley Interdisciplinary Reviews: Computational Molecular Science 2018, 8, e1327. 